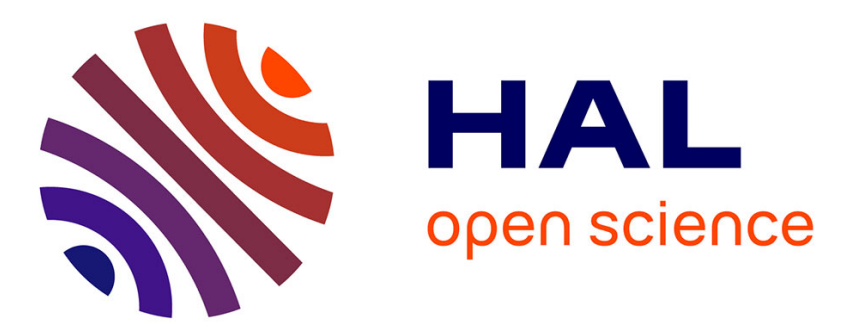

\title{
Conceptualization of a technical solution for web navigation of visually impaired people
}

Stéphanie Giraud, Pierre Thérouanne, Dirk D. Steiner

\section{To cite this version:}

Stéphanie Giraud, Pierre Thérouanne, Dirk D. Steiner. Conceptualization of a technical solution for web navigation of visually impaired people. 27ème conférence francophone sur l'Interaction HommeMachine., Oct 2015, Toulouse, France. pp.w3, 10.1145/2820619.2825004 . hal-01219068

\section{HAL Id: hal-01219068 \\ https://hal.science/hal-01219068}

Submitted on 23 Oct 2015

HAL is a multi-disciplinary open access archive for the deposit and dissemination of scientific research documents, whether they are published or not. The documents may come from teaching and research institutions in France or abroad, or from public or private research centers.
L'archive ouverte pluridisciplinaire HAL, est destinée au dépôt et à la diffusion de documents scientifiques de niveau recherche, publiés ou non, émanant des établissements d'enseignement et de recherche français ou étrangers, des laboratoires publics ou privés. 


\section{Conceptualization of a technical solution for web navigation of visually impaired people}

\author{
Stéphanie Giraud \\ Université Nice Sophia Antipolis \\ LAPCOS, 3 bd François Mitterrand. \\ Nice, 06357 France \\ stephanie.giraud@irit.fr

\section{Pierre Thérouanne} \\ Université Nice Sophia Antipolis \\ LAPCOS, 3 bd François Mitterrand. \\ Nice, 06357 France \\ pierre.therouanne@unice.fr \\ Dirk D. Steiner \\ Université Nice Sophia Antipolis \\ LAPCOS, 3 bd François Mitterrand. \\ Nice, 06357 France \\ dirk.steiner@unice.fr
}

(c) ACM , 2015. This is the author's version of the work. It is posted here by permission of ACM for your personal use. Not for redistribution. The definitive version was published in Actes de la 27ème conférence francophone sur I'Interaction Homme-M achine, 2015.

http://dx.doi.org/10.1145/2820619.2825004

\begin{abstract}
Despite the autonomy gain provided by the Web for blind people, its access for this population still remains difficult. Today, web accessibility is practically restricted to the normative accessibility guaranteed by the application of design standards. Effective accessibility, which ensures that the users can reach their goal, is therefore forgotten at the expense of the interface usability. Thus, we proposed the conceptualization of a technical solution which attains effective accessibility by solving the information filtering problem encountered by blind people. The conceptualization of this solution, supported by previous experimental results, seems promising to make web interfaces easier and faster to use by blind people.
\end{abstract}

\section{Author Keywords}

Web accessibility, blindness, web navigation, holistic approach

\section{ACM Classification Keywords}

H.1.2 [User/Machine Systems]: Human information processing, Software psychology

H.3.3 [Information Search and Retrieval]:

Information filtering 
H.5.2 [User Interfaces]: Ergonomics, User-center design

K.4.2 [Social Issues]: Assistive technologies for persons with disabilities, Handicapped persons/special needs

\section{General Terms}

Design, Human Factors

\section{Introduction}

The Web has become an unavoidable source of information and communication for blind people. Indeed, information and communications technology gives them the ability to perform activities they could not perform before such as shopping autonomously via e-commerce websites. This gain of autonomy explains the massive use of these technologies. Montagné [1] showed that the blind use Internet more frequently than the average French population and have a higher rate of computer equipment. There is therefore a real market, all the more so that the number of visually impaired people continues to increase due to the lengthening lifespan [2]. Nevertheless, the Web can also be a cause of exclusion for them. Eighty-one percent of visually impaired users consider that the access to the Web is difficult, if not impossible [3]. Many authors have highlighted the numerous problems encountered by the blind when navigating on the web with a screen reader which transcribes the website content according to a standard and serial reading of HTML content (from left to right and from top to bottom) $[4,5,6]$. For example, information gathering results in a time-consuming reading because of the reading of a large number information which are often redundant. Following previous analyses of the users' activity and needs, this paper argues for the concept of a technical solution to difficulties encountered by blind people.

\section{Existing methods for new approaches to web \\ accessibility}

Some solutions to the difficulties encountered by blind people are already provided. The "World Wide Web Consortium" (W3C) established design standards to help web designers make the Web accessible to all, as Tim Berners-Lee, the main inventor of the Web, wanted. Indeed, he stated "The Web must allow equal access to those in different economic and political situations; those who have physical or cognitive disabilities; those of different cultures; and those who use different languages that read in different directions across a page." [7]. Following this idea, blind people should have access to the same information as sighted people. To achieve this, textual equivalence is provided for each visual element present on the interface. The screen reader then provides an exhaustive transcription of website content by serially transcribing all visual information into auditory information. This exhaustive transcription is ensured by the normative accessibility of websites. This accessibility addresses the existence question (for instance, is such an object present?), guaranteeing that the task can be performed by blind users but not guaranteeing that the task is efficiently and successfully achieved. Yet, granting access is not sufficient if it is not accompanied by usability of the interface, whence the importance to respect effective accessibility as well. Indeed, effective accessibility guarantees that users can get a result or reach their goal with a reasonable amount of time and effort, thus ensuring the usability of web interfaces for blind people. 
To ensure effective accessibility, Phipps and Kelly [8], and Sloan et al. [9] proposed the holistic approach. This approach recommends taking into account the context of use including user's needs and characteristics (perceptual, cognitive, or physical abilities or disabilities), the requirements of the domain (tasks that users need to run, environmental factors, etc.), technical requirements (availability of software and assistive agents), and performance requirements (success rate, navigation time, satisfaction, etc.). According to Phipps and Kelly [8], accessible alternatives of the interface should be developed depending on the target population. Thus, the holistic approach falls within an ergonomic approach which advocates the user-centered design. The holistic approach then aims to guarantee effective accessibility, without questioning the importance of W3C standards.

\section{Application of the holistic approach}

The application of the holistic approach raises the question of cost and user acceptance. First, creating an accessible alternative of a website requires an analysis of the use context; that is how the users navigate on the Web, what their needs are, the difficulties encountered, the strategies that they set up to solve this difficulties, etc. This approach then requires time, knowledge on the specific users, and skills in order to implement the appropriate methods, causing a great cost. Second, an alternative may be accepted with difficulty by disabled people. In fact, they do not want to be treated as such and desire the same means of interaction as others for participating in social life [10]. Considering these two points, we previously applied the holistic approach in order to conceptualize an accessible alternative which fulfills the needs of the blind as well as requirements concerning cost and user acceptance.
Observations has been conducted on six blind participants and six sighted participants, who had to perform tasks using two websites (Fnac and Facebook). In addition, eleven blind participants were interviewed following navigation on the Web according their usual use. Analyses revealed a considerably long time of web navigation due to the exhaustive transcription of information. Indeed, every time an item is selected, the screen reader starts reading again from the beginning of the page and then replays all items of the web page until the desired content is reached. For example, we showed that the overall navigation time could be up to 8 times longer for blind people than for sighted people [11]. Consequently, the most important need expressed by blind people was to reach the relevant information quickly in order to accomplish their task with a reasonable amount of time and cognitive resources [12]. The satisfaction of this need implies filtering information which is not necessary to task completion: redundant information which are duplicated [13] and irrelevant information which is not topical [14, $15,16]$, such as advertising spots. We then conducted three experiments which confronted two versions of two websites which have specifically been developed for these experiments: A version which transcribed all visual information into auditory information and a version which filtered redundant and irrelevant information. Seventy-six participants realized three tasks on each websites. Results showed that filtering redundant and irrelevant information provided a substantial benefit in terms of cognitive load reduction for blind people and improvement of their performance according to three usability criteria: effectiveness, efficiency and satisfaction [17]. 


\section{Conceptualization of a technical solution}

Based on these results, we propose a technical solution which would filter redundant and irrelevant information during web navigation of blind people. In order to meet the criteria of reduced cost and user acceptance, the proposed solution is a tool inserted between the web browser and the screen reader. In this way, no intervention by designers on the websites would be required, and the solution should be compatible with any website. The technical solution, which might be a browser plug-in, would indeed modify the content of pages before the screen reader reads them. For this, this solution is based on an algorithm that parses the web page HTML content, compares the items in the page to those in the previously visited pages and to those in an on-line shared and self-powered database, and accordingly filters unnecessary information, as presented in Figure 1 below. The Figure shows in a simplified manner an example of web navigation by a blind user with and without the technical solution. To start, the user enters page 1 of the website, then selects a menu link. Once on page 2 , the user selects a link from menu 2 to enter page 3 and listen to the desired content. The filtering of irrelevant and redundant information provided by the technical solution reduces the number of steps (information areas read by the screen reader) from 11 to 4 in this example.

Thus, this solution would offer a considerable benefit in terms of cognitive load, effectiveness, efficiency, and satisfaction for web navigation by blind people. Nevertheless, this solution meets only one of the users' needs: information filtering which allows reaching a goal with a reasonable amount of time and effort, ensuring effective accessibility. This is why the respect of standards, such as those of W3C, ensuring normative accessibility should not be neglected in order to solve other problems encountered by blind people, such as the inability to read captchas ${ }^{1}$.

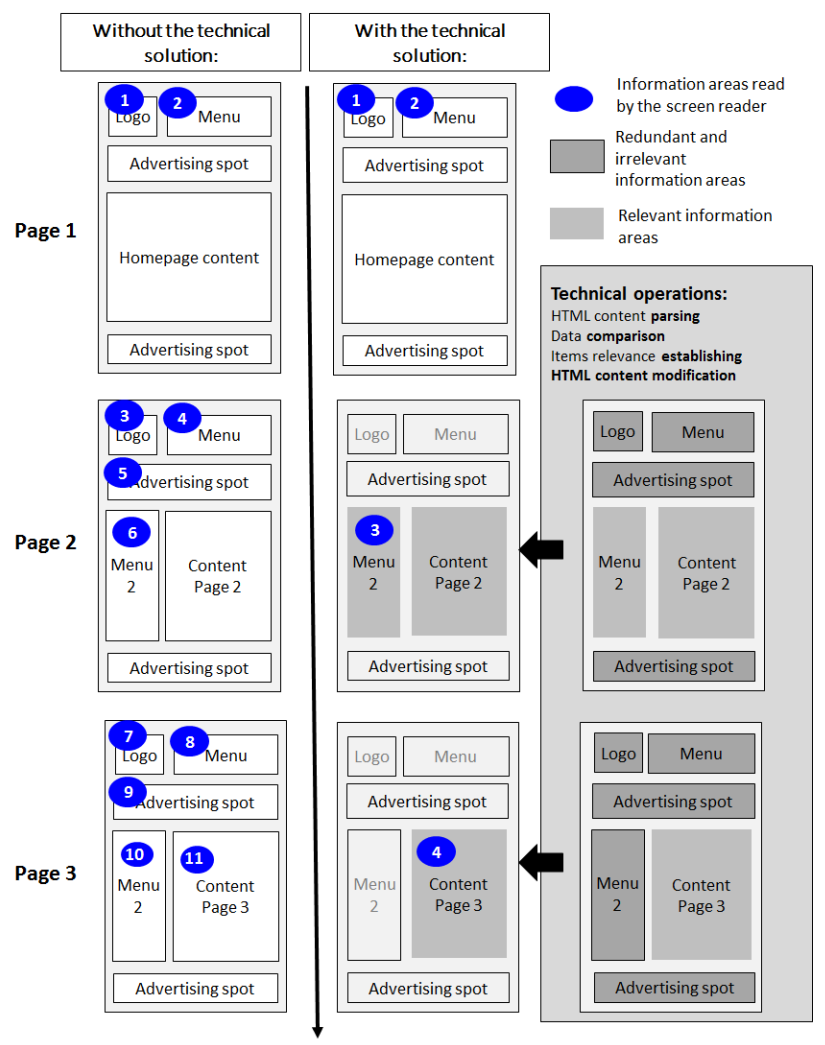

Figure 1. The principle of the technical solution which filters the redundant and irrelevant information.

\footnotetext{
${ }^{1}$ A captcha is an on-line test that ensures the action is being
} performed by a human being and not by a computer. 


\section{Conclusion}

The technical solution resulting from the application of the holistic approach should provide a substantial gain in terms of cognitive load reduction and the improvement of interface usability according to the three usability criteria: effectiveness, efficiency, and satisfaction. Nevertheless, the benefit provided by information filtering has been shown in experimental conditions which limited keyboard use [see 17]. Indeed, in our three experiments, blind participants could only use three keys whereas they usually use a large number of keys or key combinations [12]. For example, blind people use the "down arrow" key to move to the next link, which allows for moving faster in the interface and for avoiding listening to all information. Consequently, the benefit provided by the filtering of irrelevant and redundant information could be reduced in natural conditions. Nevertheless, blind users are not satisfied with the "down arrow" key use because it requires temporal and cognitive resources during decision-making to move to the next link. Moreover, the number of keys used depends on the expertise level of blind users; the novice blind using very few keys. The technical solution would then be all the more beneficial for them. Furthermore, we noticed a high satisfaction rate of blind people resulting from information filtering [17]. Thus, it is reasonable to think that the benefit provided by this solution remains substantial in natural conditions. That said, despite we validated the principle of the technical solution, it has not effectively been implemented. Thus, it will be necessary to develop it in order to ensure that the benefit arises in natural conditions, that is, with all interaction means that blind people usually use. For this purpose, existing technologies (JavaScript, databases, Ajax, etc.) should be used for the development. In addition, evaluation of the technical solution would also allow for assessing the acceptance level of this solution by blind users. Indeed, even if this solution allows blind people to use the same interfaces as sighted people, the initiatives taken by the technical solution raise the problem of control left to the user. Bastien and Scapin [18] advised that users should have control capabilities over ongoing processing (user control criteria). This solution therefore runs counter to this criterion, bringing up the question of real or perceived reliability. Blind people might not trust a technical solution which may filter some information they wish to hear. Thus, in future work, we could carry out two types of methods for the evaluation of this technical solution. First, semi-structured interviews could be led in order to collect the blinds' perceptions of such a solution (advantages, risks, opportunities) [19]. Second, a user-test could be conducted in order to assess the usability of this solution. Thanks to this evaluation, we could therefore test whether the solution would be accepted or rejected according to its ease of use and its relevance, which is a necessary criterion for it to be used. Once evaluation conducted, one can implement one plug-in per web browser (Internet Explorer, Firefox, Google Chrome, Safari, etc.). In conclusion, the conceptualization of the technical solution resulting from the application of the holistic approach is a first step for the development of a tool which would improve the usability of web interfaces for blind people. This solution seems promising and could be developed to be used in the daily life of blind people.

\section{References}

[1] Montagné, G. L'inclusion des personnes aveugles et malvoyantes dans le monde d'aujourd'hui. Paris: 
Ministère du travail, des relations sociales et de la solidarité (2007).

[2] World Health Organization. Global data on visual impairments 2010. Retrieved from

http://www.who.int/blindness/GLOBALDATAFINALforwe

b.pdf

[3] HandiCapZero. Enquête 2005 : qui êtes-vous ? Retrieved from

http://www.handicapzero.org/fileadmin/user_upload/co ntenu/Enquete/Telechargez_I_enquete_complete_en_P DF.pdf

[4] Buzzi, M. C., Buzzi, M., Leporini, B., \& Akhter, F. Usability and Accessibility of eBay by Screen Reader. In Proc. USAB 2009, Springer 2009, 500-510.

[5] Buzzi, M. C., Buzzi, M., Leporini, B., Mori, G., \& Penichet, V. M. R. Accessing Google Docs via Screen Reader. In Proc. ICCHP 2010, Springer 2010, 92-99.

[6] Lazar, J., Allen, A., Kleinman, J., \& Malarkey, C. What frustrates screen reader users on the web: $A$ study of 100 blind users. International Journal of Human-Computer Interaction 22, 3 (2007), 247-269.

[7] Dardailler, D. A World of Stakeholders: Lessons from Global Outreach (2008). Retrieved from http://www.w3.org/2008/04/dd-global.html

[8] Phipps, L., \& Kelly, B. Holistic approaches to elearning accessibility. ALT-J Association for Learning Technology Journal 14, 1 (2006), 69-78.

[9] Sloan, D., Heath, A., Hamilton, F., Kelly, B. Petrie, H., \& Phipps, L. Contextual web accessibility Maximizing the benefit of accessibility guidelines. In Proc. WWW 2006, ACM Press (2006).

[10] Nevile, L. User-centred accessibility supported by distributed, cumulative authoring. In Proc. AusWeb 2005.
[11] Giraud, S., Colombi, T., Russo, A. \& Thérouanne, P. Accessibility of Rich Internet Applications for blind people. In Proc. CHItaly 2011, ACM Press (2011), 163166

[12] Giraud, S. L'accessibilité des interfaces informatiques riches pour les déficients visuels (Doctoral dissertation, 2014). Retrieved from http://www.theses.fr/2014NICE2035

[13] Le Bohec, O., \& Jamet, E. Les effets de redondance dans l'apprentissage à partir de documents multimédia. Travail Humain 68, 2 (2005), 97-124.

[14] Grice, H. P. Logic and Conversation. In Peter Cole and Jerry L. Morgan (eds.) Syntax and Semantics, 3 (1975), 41-58.

[15] Wilson, D., Sperber, D., Kant, E., \& Foucault, M. L'interprétation des énoncés. Communications, 30 (1979), 80-94.

[16] Soergel, D. Indexing and retrieval performance: The logical evidence. American Society for Information Science 45, 8 (1994), 589-599.

[17] Giraud, S., Thérouanne, P., \& Steiner, D. Holistic approach to web accessibility: a better usability for visually impaired users (in preparation).

[18] Bastien, C., \& Scapin, D. L. Ergonomic Criteria for the Evaluation of Human-Computer

interfaces. Rocquencourt : Institut National de recherche en informatique et en automatique (1993).

[19] Bobillier Chaumon, M.-E., Dubois, M., \& Retour, D. L'acceptation des nouvelles technologies d'information : le cas des systèmes d'information dans le milieu bancaire. Psychologie du Travail et des Organisations 12, 4 (2006), 247- 262. 